\title{
Wavelet-based power management for hybrid energy storage system
}

\author{
Masoud MASIH-TEHRANI ${ }^{1}$ (D), Mohammad Reza HA'IRI YAZDI ${ }^{2}$, \\ Vahid ESFAHANIAN ${ }^{2}$, Masoud DAHMARDEH ${ }^{3}$ (D, Hassan NEHZATI ${ }^{4}$
}

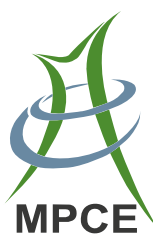

\begin{abstract}
A wavelet-based power management system is proposed in this paper with a combination of the battery and ultracapacitor (UC) hybrid energy storage system (HESS). The wavelet filter serves as a frequency-based filter for distributing the power between the battery and UC. In order to determine the optimal level of wavelet decomposition as well as the optimal activation power of the wavelet controller, an optimization procedure is established. The proposed frequency-based power management system moderates the usage of battery current, consequently improving its lifetime. Compared with the
\end{abstract}

CrossCheck date: 28 February 2019

Received: 14 April 2018/Accepted: 28 February 2019/Published online: 31 May 2019

(C) The Author(s) 2019

$\triangle$ Masoud DAHMARDEH

mdahmardeh@iust.ac.ir

Masoud MASIH-TEHRANI

masih@iust.ac.ir

Mohammad Reza HA'IRI YAZDI

myazdi@ut.ac.ir

Vahid ESFAHANIAN

evahid@ut.ac.ir

Hassan NEHZATI

hassan.nehzati@gmail.com

1 Vehicle Dynamical Systems Research Laboratory, School of Automotive Engineering, Iran University of Science and Technology, Tehran, Iran

2 School of Mechanical Engineering, College of Engineering, University of Tehran, Tehran, Iran

3 School of Automotive Engineering, Iran University of Science and Technology, Tehran, Iran

4 Vehicle Fuel and Environment Research Institute, University of Tehran, Tehran, Iran conventional threshold-based power management systems, the proposed system has the advantage of enhanced battery and UC power management. A $\mathrm{LiFePO}_{4}$ battery is considered and its life loss is modeled. As a case study, an electric motorcycle is evaluated in the federal test procedure (FTP) driving cycle. Compared with a conventional energy storage system (ESS) and a state of available power (SoP) management systems, the results show an improvement for the battery lifetime by $115 \%$ and $3 \%$, respectively. The number of battery replacements is increased, and the energy recovery is improved. The 10-year overall costs of the proposed HESS strategy using wavelet are 1500 dollars lower, compared with the ESS.

Keywords Wavelet filter, Hybrid energy storage system (HESS), Power management system, Ultracapacitor (UC), Lithium life loss model, Battery, Energy storage cost

\section{Introduction}

Electric vehicles (EVs) have significantly lower mileage cost, reduced air pollution, less petroleum dependence, and better performance over conventional internal combustion engine (ICE) based vehicles [1]. Energy storage system (ESS) is the key factor in EV performance and reliability [2] as well as the main limiting factor during their commercialization process [3]. Due to the heavy, costly and bulky nature of a conventional ESS, EV characteristics, such as mileage is limited [4]. Although, the benefit of using EVs over ICE vehicles is clear in terms of fuel economy and pollution. However, the short service life of ESS and its replacement costs are the limiting factor for commercialization of EVs [5]. With the ongoing development of batteries in terms of increasing the capacity while 
reducing costs, EVs are becoming popular [6]. As a result, more and more efforts are devoted to improve ESS performance [7, 8].

The conventional ESS (battery or ultracapacitor(UC)) has either high energy or high power specifications [9]. Typically, the designer should oversize either the battery or $\mathrm{UC}$, in order to meet both the energy and power demands of the EV, which is not practical due to the increase of cost, size and weight of the system [10]. Therefore, high energy/ power characteristics of the battery/UC are combined to form a new ESS and provide the demand energy/power of the vehicle [11]. This provides an ESS with low cost and high performance while reducing the weight and improving the battery lifetime [12]. Recently, the idea of coupling battery and UC as a hybrid energy storage system (HESS) is proposed in order to moderate current stresses and peaks of the battery. This enables the designer to employ a smaller battery at lower cost while improving its lifetime $[10,13]$.

The HESS performance is strongly affected by its power distribution system (PDS) [14, 15]. Various HESS power distribution strategies are developed in recent years [16], and this field is getting more and more attention. Besides, there are limited reports on frequency-based control strategies. A dynamic programming strategy is developed in [17] for power distribution between battery and UC. This strategy develops an optimum controller for a specific driving cycle and is useful for off-line applications. Simple controllers such as battery-based [18] and UC-based [19] power management strategies for HESS are proposed, which are based on the battery and UC threshold levels (maximum and minimum power capacities). These controllers are online and show good performance.

A model predictive controller for power management of a plug-in hybrid EV with a hybrid ESS is designed in [20]. A cascade and adaptive control strategy is proposed for load compensating of a battery/UC HESS [21]. Adaptive HESS controller is proposed in [22, 23]. Other power management strategies are reported in the literature, such as fuzzy [24], optimal [25], mode decomposition [26], model predictive [27], dynamic programming [28], and neural network [29] strategies. Recently, the authors present a method based on the state of available power (SoP) and predict the power limitations for a given time frame in the future [30]. It is shown that the battery lifetime is improved by 2.6 times.

The basic idea of a frequency-based power management strategy is to moderate the battery current. The UC is assigned to provide the high frequency portion of the demand power, while the battery supports the remaining part. Wavelet filter is a powerful yet simple energy management method employed for different applications. The use of wavelet in energy management system for fuel cell vehicle [31], wind power [32], photovoltaic (PV) system [33], and wind-PV hybrid power [34] are reported. A frequency-based power management strategy is proposed for the HESS using Fourier method for a periodic pulsed current load [35].

This paper presents a new HESS power management (frequency-based) system to control the battery current using wavelet filter. A three-level Haar wavelet filter is employed. As a case study, powertrain modeling of an electric motorcycle is introduced in the Section 2. Section 3 discusses the HESS design procedure. A lifetime model for the Lithium iron phosphate $\left(\mathrm{LiFePO}_{4}\right)$ battery, UC model, and HESS costs are discussed. Section 4 introduces the HESS power management. At first, a conventional UC-based power management is introduced, followed by SoP power management system. The waveletbased power management system is discussed afterwards. Section 5 discusses the principles and tuning of power management optimization. Results and conclusion are presented in Sections 6 and 7.

\section{Electric motorcycle modeling}

An electric motorcycle (AVITA) has been designed and manufactured at Sharif University of Technology, Tehran, Iran. The high voltage bus of AVITA is provided by the batteries. Recently, the conventional Ni-MH batteries employed in EVs are replaced by Lithium-based batteries [36]. Particularly, the $\mathrm{LiFePO}_{4}$ battery is suggested to be a suitable option to be employed in EVs due to the good chemical and thermal behavior as well as its low cost [37]. A capacity depletion behavior and lifetime modeling of this battery are proposed in [17]. The battery cell of the electric motorcycle is "high capacity LFP26650P power cell". The main characteristics of the electric motorcycle and the main specifications of its powertrain are listed in Tables 1 and 2, respectively.

Figure 1 shows a schematic power flow model of the driver, electric motorcycle powertrain model, vehicle dynamics, and the storage section. The core of the

Table 1 Main characteristics of electric motorcycle

\begin{tabular}{ll}
\hline Characteristic & Value \\
\hline Total mass (with driver) & $250 \mathrm{~kg}$ \\
Rolling resistance coefficient & 0.003 \\
Drag coefficient & 0.40 \\
Frontal area & $0.60 \mathrm{~m}^{2}$ \\
Tire radius & $0.24 \mathrm{~m}$ \\
\hline
\end{tabular}


Table 2 Main specifications of the electric motorcycle powertrain

\begin{tabular}{ll}
\hline Component & Specification \\
\hline High voltage bus & Voltage: $70 \mathrm{~V}$ \\
Traction motor & Power: $6 \mathrm{~kW}($ Peak $12 \mathrm{~kW})$ \\
& Torque: $70 \mathrm{Nm}($ Peak $140 \mathrm{Nm})$ \\
& 286 Lithium LiFePO 4 cells \\
Battery & (22 cells in series and 13 in parallel) \\
& Cell voltage: $3.3 \mathrm{~V}$ (Maximum $3.5 \mathrm{~V})$ \\
& Cell capacity: 2.6 Ah (Totally $33.8 \mathrm{Ah})$ \\
& Cell continuous discharge current: $10 \mathrm{~A}$ \\
& Cell peak discharge current: $50 \mathrm{~A}$ \\
& Cell charge current: $5 \mathrm{~A}$ \\
& Cycle life: 2000 at $80 \% \mathrm{DoD}$ \\
\hline
\end{tabular}

Note: DoD stands for the depth of discharge

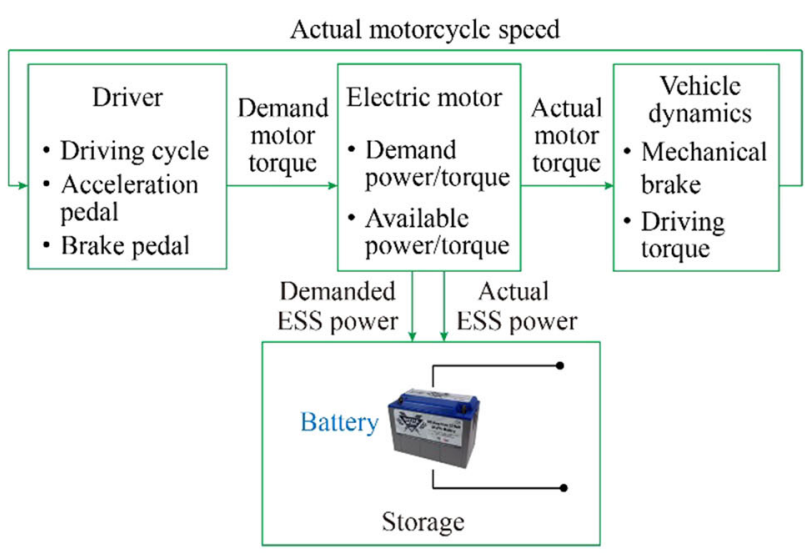

(a) ESS

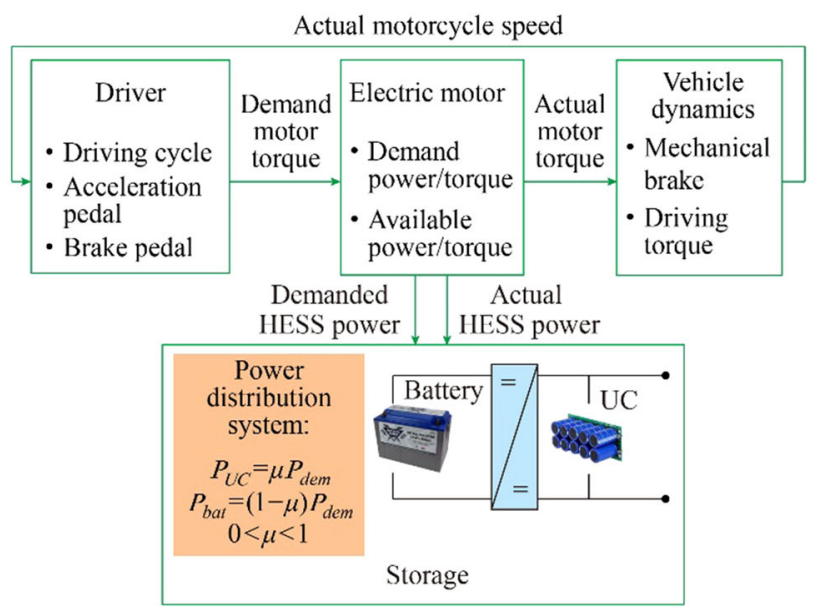

(b) HESS

Fig. 1 Schematic power flow model of the electric motorcycle with ESS and HESS powertrain model is similar to that presented in [38]. This modeling platform has been used for hybrid electric [39], hybrid flywheel [40] and hybrid hydraulic [41] powertrain simulation and design. The results show that the developed powertrain passes the criteria, some of which are listed in Table 3.

Figure 1a shows the electric motorcycle equipped with ESS, where the demand and actual ESS power are provided by the ESS, e.g. the battery. On the other hand, Fig. 1b shows the electric motorcycle equipped with HESS. The power demand is split between the battery and UC. A portion of the demand power $(\mu)$ is provided by the UC, while the rest of the demand power $(1-\mu)$ is provided by the battery, where $0<\mu<1$. In the next section, different HESS architecture and power management systems are introduced and discussed.

\section{HESS design}

\subsection{Battery lifetime model}

The modeling and calculation of the state of charge (SoC) for the battery and UC are important while evaluating the HESS [42]. The generalized $\mathrm{LiFePO}_{4}$ battery life model is reported in [43], and is given by (1).

$Q_{\text {loss }}=B \exp \left(\frac{31700+370.3 \times C_{\text {rate }}}{R T}\right)\left(A_{h}\right)^{0.55}$

where $Q_{\text {loss }}$ is the percentage of capacity loss; $B$ is the preexponential factor depending on the $C_{\text {rate }}$, which is the ratio of battery current to the battery capacity; $R$ is the gas constant; $T$ is the absolute temperature; $A_{h}$ is the Ahthroughput expressed as $A_{h}$ equals to cycle number multiplied by DoD multiplied by full cell capacity. This equation is proposed in [44]. The values of $B$ at different $C_{\text {rate }}$ are listed in Table 4 [43].

The life capacity $A_{h}$ which is a function of the current for the $\mathrm{LiFePO}_{4}$ battery cell with $2.6 \mathrm{Ah}$ in each battery current is obtained using (1). And it is listed in Table 5 [17]. The life capacity is defined as the amount of charge that the battery can provide at a specific current before its capacity loss reaches $20 \%$ [17].

Table 3 Design criteria of electric motorcycle powertrain

\begin{tabular}{lll}
\hline Criterion & Target & Result \\
\hline $\begin{array}{l}\text { Driving range in FTP driving cycle } \\
\begin{array}{l}\text { Driving range in highway }(90 \mathrm{~km} / \mathrm{h} \\
\text { constant speed) }\end{array}\end{array}$ & $100 \mathrm{~km}$ & $104 \mathrm{~km}$ \\
\begin{tabular}{l} 
Maximum speed \\
\hline
\end{tabular} & $110 \mathrm{~km} / \mathrm{h}$ & $117 \mathrm{~km} / \mathrm{h}$ \\
\hline
\end{tabular}


Table 4 Values of $B$ at different $C_{\text {rates }}$

\begin{tabular}{ll}
\hline$C_{\text {rate }}$ & Value of $B$ \\
\hline C/2 & 31630 \\
2C & 21681 \\
$6 \mathrm{C}$ & 12934 \\
$10 \mathrm{C}$ & 15512 \\
\hline
\end{tabular}

$10 \mathrm{C}$

5512

Table 5 Life capacity at different battery current

\begin{tabular}{ll}
\hline Current (A) & Life capacity $(\mathrm{Ah})$ \\
\hline 1 & 1452 \\
10 & 2298 \\
15 & 2085 \\
20 & 1278 \\
25 & 641 \\
30 & 238
\end{tabular}

For analyzing the vehicle performance, "driving cycles" are employed, where the vehicle speed is reported for a specific period of time to demonstrate a certain driving pattern. Generally, standard driving cycles are employed to estimate fuel consumption, vehicle emission and traffic assessment. It is shown that the performance of ESS or HESS depends on the aggressiveness of the driving cycle [45]. Therefore, in order to design and size the HESS, a specific driving cycle is considered to achieve the optimized battery size and associated costs.

The driving cycle capacity loss is given by [17]:

$Q_{\text {loss }, D C}=\sum_{k=0}^{t_{D C}} \frac{I_{k} \frac{\mathrm{d} t}{3600}}{L_{C}\left(I_{k}\right)}$

where $I_{k}$ is the battery current at the $k^{\text {th }}$ time step, and $k$ is in the range of $\left(0\right.$, driving cycle duration or $\left.t_{D C}\right) ; \mathrm{d} t$ is the time step of the calculation; $L_{C}$ is the life capacity and is a function of $I_{k}$ determined by Table 5. Equation (3) calculates the 10-year capacity loss $Q_{\text {loss, } 10 y}$ [17]. It is a merit of how much loss is introduced to the battery. The obtained value from (3) is rounded up to the next integer, which shows the number of battery replacements, assuming the obtained value is greater than 1. Assuming consistent daily travel itineraries, the driving cycle capacity loss is divided by the driving cycle duration, multiplied by 3600 (to convert seconds to an hour), multiplied by 8 (to convert hours to a working day), multiplied by 250 (to convert working days to a working year) and then multiplied by 10 , to estimate the 10 -year capacity loss.

$$
Q_{l o s s, 10 y}=Q_{l o s s, D C} / t_{D C} \times 3600 \times 8 \times 250 \times 10
$$

Battery lifetime is expressed by (4). The factor of " 0.2 " is used, since the battery needs to be replaced once it reaches the $20 \%$ of its capacity.

$T_{\text {life, bat }}=0.2 \frac{C_{\text {bat }}}{Q_{\text {loss }, D C}} \frac{t_{D C}}{3600 \times 8 \times 250}$

where $C_{b a t}$ is the battery capacity in Ah.

\subsection{UC model}

Table 6 lists the UC module characteristics. Compared with the $\mathrm{LiFePO}_{4}$ battery, power specification of the UC $(14.4 \mathrm{~kW} / \mathrm{kg})$ is much larger than that of the battery $(1.53$ $\mathrm{kW} / \mathrm{kg})$, and the energy specification of the UC $(4.00 \mathrm{Wh} /$ $\mathrm{kg})$ is much smaller than that of the battery $(134.55 \mathrm{Wh} /$ $\mathrm{kg}$ ).

\subsection{HESS cost}

The ESS cost is a major obstacle which should be overcome to make the EVs to be viable. Studies discuss the market trends and roadmaps for ESSs which show ongoing characteristics improvement and reduced costs. On the other hand, the reported studies and the number of patents on ESSs are growing fast in recent years.

The costs associated with $\mathrm{LiFePO}_{4}$ batteries, UCs and DC/DC converters are reported in literature. The configuration of the proposed HESS is "active topology" [7] with one DC/DC converter.

The cost of HESS for a 10-year period is calculated as:

$$
\begin{aligned}
C_{H E S S, 10 y}= & C_{\text {ceil }} Q_{\text {loss }, 10 y} \times 2.5 \times 500+12 \times 50+0.027 \\
& \times 15000
\end{aligned}
$$

The following assumptions are made: a $2.5 \mathrm{kWh}$ battery is used with the associated cost of $500 \$ / \mathrm{kWh}$. A $12 \mathrm{~kW}$ DC/DC converter is employed with the associated cost of $50 \$ / \mathrm{kW}$. A $0.027 \mathrm{kWh}$ UC at the cost of $15000 \$ / \mathrm{kWh}$ is used.

Table 6 UC module characteristics

\begin{tabular}{ll}
\hline Capacitance (F) & 165 \\
Peak current (A)/power (kW) (1second) & $4000 / 194.4$ \\
Maximum continuous current (A)/power (kW) & $150 / 7.3$ \\
Nominal voltage (V) & 48.6 \\
Energy (Wh) & 54 \\
Weight (kg) & 13.5 \\
\hline
\end{tabular}




\section{HESS power management}

The HESS power management strategy strongly affects its performance [46]. In this paper, a wavelet-based power management based on the frequency of the demand current is developed to moderate the battery current fluctuations. The design targets are the battery lifetime and vehicle fuel consumption.

\subsection{UC-based power management}

Each HESS needs a power distribution control strategy (PDCS). The UC-based strategy is a conventional, yet simple PDCS which is in [18, 19]. A UC-based PDCS is proposed in [17]. At the beginning, the UC power is set to the demand power $\left(P_{U C}=P_{d e m}\right)$. However, the UC power is limited by two bounds: the minimum and maximum levels of UC power, $P_{U C \text {, min }}$ and $P_{U C, \max }$, respectively. If there is any demand power left, which the UC could not provide, it would be supplied by the battery $\left(P_{b a t}=P_{d e m}-\right.$ $\left.P_{U C}\right)$. Similarly, the battery power is limited by two bounds: the minimum and maximum levels of battery power, $P_{b a t, \min }$ and $P_{b a t, \max }$, respectively.

\subsection{SoP management}

Another approach for power distribution management of HESS is based on the SoP, which is predicted power limits for a pre-defined time frame in the future. In other words, the energy storage power limitations are predicted for a certain period of time, in order to prevent it from violating maximum/minimum voltage and state of charge $(\mathrm{SoC})$ constraints. Although the idea is not new [47], it is getting more attention recently $[30,48,49]$. Besides a few studies, this concept is rarely used along with the UC [30]. SoP-based PDS is in [30].

The maximum discharge power and minimum charge power based on the SoP is given by (6) and (7), respectively.

$P_{U C, \text { max }}^{d i s, S o}=I_{U C, \text { max }}^{d i s, t o t}\left\{V_{O C, U C}\left(S o C_{U C}-I_{U C, \text { max }}^{d i s, t o t} \frac{\Delta t}{C_{U C}}\right)-R_{i n, U C} I_{U C, \text { max }}^{d i s, t o t}\right\}$

$P_{U C, \text { min }}^{c h g, S o P}=I_{U C, \text { min }}^{c h g, t o t}\left\{V_{O C, U C}\left(S o C_{U C}-I_{U C, \text { min }}^{c h g, t o t} \frac{\Delta t}{C_{U C}}\right)-R_{i n, U C} I_{U C, \text { min }}^{c h g, t o t}\right\}$

where $\Delta t$ is the specific time frame; $S o C_{U C}$ and $V_{O C, U C}$ are the $\mathrm{SoC}$ and open circuit voltage of UC during each time frame, respectively; $C_{U C}$ and $R_{i n, U C}$ are the capacitance and internal resistance of the UC, respectively; and $I_{U C, \text { max }}^{d i s, t o t}$ and $\Delta t I_{U C, \text { min }}^{c h g, t}$ are the maximum UC current limits for the discharge and charge modes, respectively.
Detailed work of Section 4 can be found in [30].

\subsection{Wavelet-based power management}

The wavelet-based power management system is developed based on the frequency of the demand current to reduce the fluctuations of the battery current. A proper frequency filter is required for power management of the HESS. In this paper, the wavelet filter is used to distribute power between the battery and UC. The ESS demand power is analyzed by the wavelet filter and is divided into the high and low frequency parts. The UC provides the high frequency part, even if the demand power is lower than the maximum continuous power of the battery. The remaining part (low frequency one) is delivered by the battery.

Equation (8) presents the Morlet-Grossmann definition of the continuous wavelet transform (CWT) for a one-dimensional signal.

$W(\lambda, u)=\int_{R} x(t) \frac{1}{\sqrt{\lambda}} \psi\left(\frac{t-u}{\lambda}\right) \mathrm{d} t \quad \lambda>0, u \in R$

where $t$ is the time; $u$ is the location; $W$ is the wavelet coefficient; $x$ is the initial signal; $\lambda$ is the size factor; and $\psi$ is the mother function.

The reverse transform of continuous wavelet for reconstruction of the original signal $x(t)$ is given by:

$x(t)=\frac{1}{K_{\psi}} \int_{R^{+}} \int_{R} W(\lambda, u) \frac{1}{\sqrt{\lambda}} \psi \frac{t-u}{\lambda} \frac{\mathrm{d} \lambda \mathrm{d} u}{\lambda^{2}}$

where $K_{\psi}$ is a constant value.

One of the most well-known mother wavelets is Haar wavelet, which has the shortest filter length in time domain compared with other wavelet basis. Haar is the simplest wavelet, which is equal to its inverse [50]. Therefore, the Haar wavelet function is the fastest for calculations and makes the decomposition calculations much simpler compared with the other basis due to the realization of wavelet transform strategy in a real-time situation [51]. In this paper, the Haar wavelet filter presented by (10) is employed for the decomposition of the demand power to distribute it between the battery and UC.

$\psi(t)= \begin{cases}1 & t \in[0,1 / 2) \\ -1 & t \in[1 / 2,1) \\ 0 & \text { otherwise }\end{cases}$

Unlike CWT, the discrete wavelet transform (DWT) is employed to decompose a discrete signal into different resolution levels. The DWT and its inverse representations are given by (11) and (12), respectively. 


$$
\begin{array}{r}
W(\lambda, u)=\int_{R} x(t) \frac{1}{\sqrt{\lambda}} \psi \frac{t-u}{\lambda} \mathrm{d} t \\
\lambda=2^{j}, u=k 2^{j}, j, k \in Z \\
x(t)=\sum_{j \in Z} \sum_{k \in Z} W(j, k) \psi_{j, k}(t)
\end{array}
$$

By using the Haar-wavelet-based $N$-channel filter bank [52], the input signal $x(t)$ is decomposed by a low-pass filter $H_{0}(z)$ and high-pass filters $H_{k}(z), k=1,2, \ldots, N-1$, into subband channels with the signal at that particular subband channel. The reconstruction filters $G_{k}(z), k=$ $1,2, \ldots, N-1$ are used for signal reconstruction [51].

The optimal level of wavelet decomposition should be chosen properly in order to meet the calculation simplicity and frequency requirements for a real-time system. For each wavelet decomposition level, the results are calculated and compared with the other cases to choose the best number of levels. Consider $N=2$, then the decomposition and reconstruction filters become $\left[H_{1}(z), H_{0}(z)\right]^{\mathrm{T}}$ and $\left[G_{1}(z), G_{0}(z)\right]^{\mathrm{T}}$, respectively.

The three-level Haar wavelet decomposition and reconstruction is employed. The down-sampling and upsampling methods are used in the decomposition and reconstruction processes, respectively. The data size decreases by half in down-sampling operations while it doubles in the up-sampling operations [51].

Using the multilevel Haar wavelet filter, the electric power demand of the vehicle is decomposed to the smooth slow-variation power signal $x_{0}(n)$ and the transients $\left(x_{1}(n)+x_{2}(n)+\ldots+x_{N}(n)\right)$ power signal. The obtained power signals are distributed between battery and UC using the wavelet-based power management system.

\section{Principles and tuning of power management optimization}

Figure 2 shows the proposed power management system which is based on an initial decision on how to employ the wavelet controller. The demand power is received by the power management system. If the demand power is greater than a certain power level (activation power of the wavelet controller, $\left.p_{p}\right)$, the wavelet controller is engaged and determines the battery and UC power shares accordingly.

However, if the demand power is less than the activation power, a simple UC-based controller is engaged and the battery and UC powers are determined. The determined values are then checked with the battery/UC limits to make sure they do not exceed the power limits.

In order to determine the optimal level of wavelet decomposition as well as the optimal activation power, an

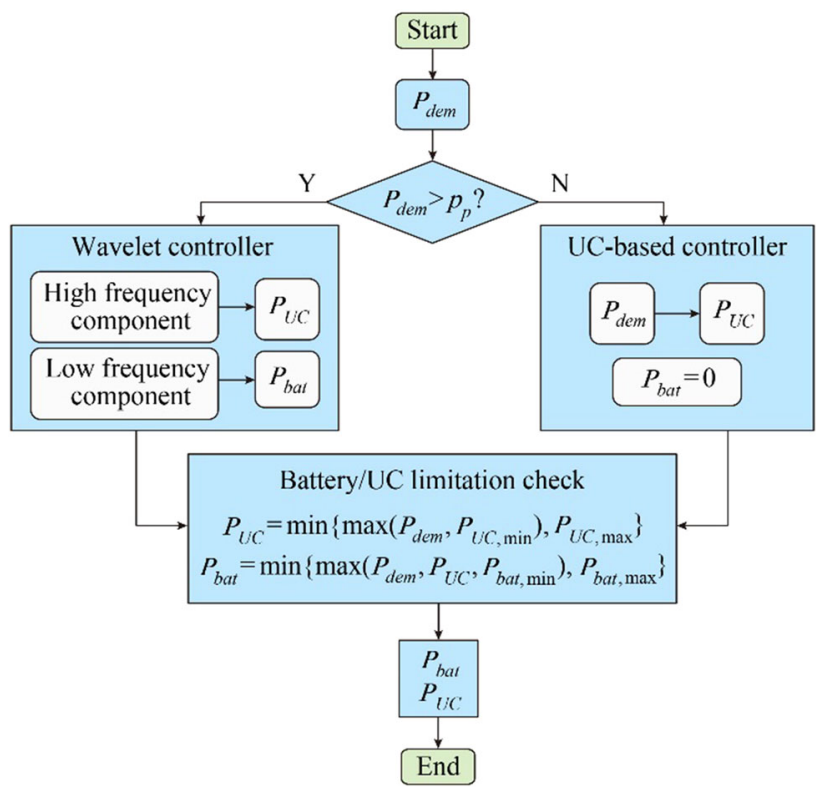

Fig. 2 The proposed power management system

optimization procedure is established as follows. Integer genetic algorithm is employed [53]. The target is defined as the battery capacity loss during one driving cycle $\left(Q_{l o s s, D C}\right)$, which needs to be minimized. Design variables are the level of wavelet decomposition $n_{i}$ and the activation power $p_{p}$. The optimization parameters are listed in Table 7.

Figure 3 shows the contour plot of the optimization objective function with respect to the $p_{p}$ and $n_{i}$, respectively. It is found that the battery capacity loss is in the range of $1.46 \times 10^{-5}$ Ah to $1.9 \times 10^{-5} \mathrm{Ah}$.

By analyzing the optimization results, the best capacity loss is found to be $1.46 \times 10^{-5}$ Ah which is achieved when the conditions is: $n_{i}=29, p_{p}=1800 \mathrm{~W}$.

\section{Results}

After finding the optimal conditions for the wavelet controller, they are employed within the wavelet controller throughout this section. Figure 4 shows three plots for the UC power share during the FTP driving cycle. The top

Table 7 Power management optimization problem

\begin{tabular}{ll}
\hline Cost function & $\begin{array}{l}Q_{\text {loss }, D C} \\
(\text { Equation }(2))\end{array}$ \\
\hline Design variables & $n_{i}$ \\
& $p_{p}$ \\
Variable bounds & $1 \leq n_{i} \leq 30, \quad-8000 \leq p_{p} \leq 8000$ \\
\hline
\end{tabular}




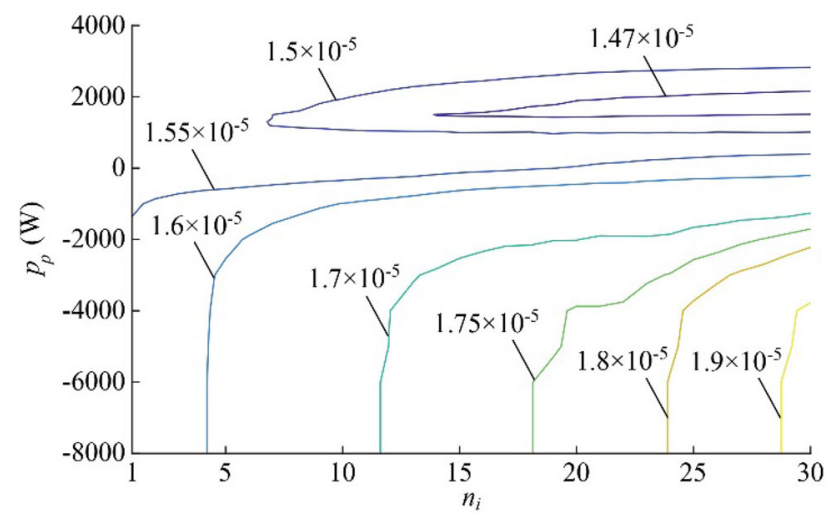

Fig. 3 Contour plot of $Q_{\text {loss }, D C}$ for the proposed power management system

graph shows the power share for the whole FTP driving cycle. In order to clarify the results, the bottom-left graph shows an example of the UC discharging mode, while the bottom-right graph shows a charging instance as an example. The solid green line is for the UC-based PDS $\left(P_{U C, U}\right)$, the solid red line is for the SoP-based PDS $\left(P_{U C, P}\right)$ and the solid blue line is for the proposed wavelet PDS $\left(P_{U C, W}\right)$. As shown in Fig. 4, there is a large peak for the UC-based strategy at around $195 \mathrm{~s}$. This is not desirable, since the UC drains quickly and would be idle for the moments after the peak. On the other hand, the proposed wavelet PDS has a higher UC power share for most of the time, compared with the other two methods.

Another advantage of the proposed wavelet PDS is in the regenerative mode. As shown in Fig. 4, during the regenerative braking, the UC performs more efficiently under the wavelet PDS strategy, by providing larger UC power share to efficiently capture the recovery energy. Overall, it is noticed that the UC performance is the best for the wavelet PDS, followed by the SoP-based PDS and UC-based PDS.

An important parameter for the ESS is the SoC, which is a measure of the available energy. Figure 5 plots the UC SoC for the whole and interval duration of the FTP driving cycle. As discussed, the most effective UC power share belongs to the wavelet PDS, therefore, it is expected that the UC SoC remains higher for this strategy, compared with the other two strategies.

These results are in agreement with the ones reported by Fig. 4. This is due to the improved discharging/charging of the UC for the wavelet PDS, compared with the other two methods.

Figure 6 plots the battery power consumption for the whole and interval duration of the FTP driving cycle. As mentioned, the wavelet PDS engages the UC more efficiently during the discharging/charging modes, which enables the battery to have the lowest power consumption.

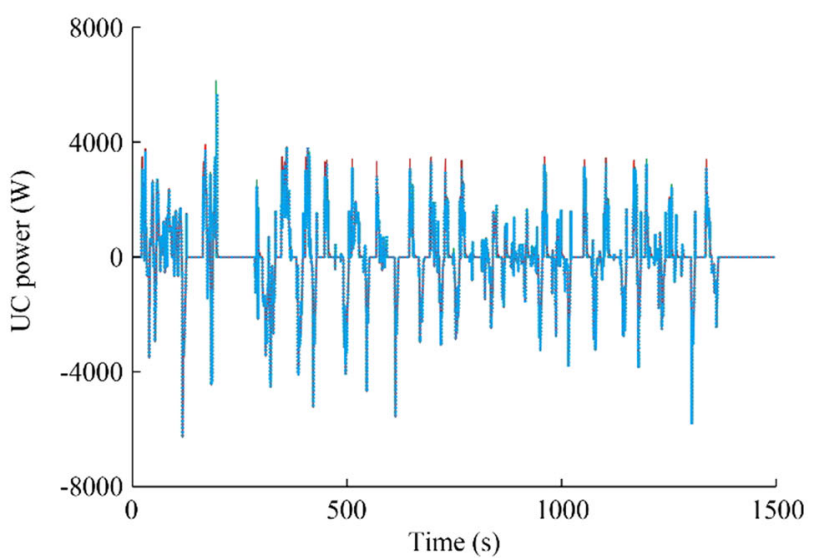

(a) Whole

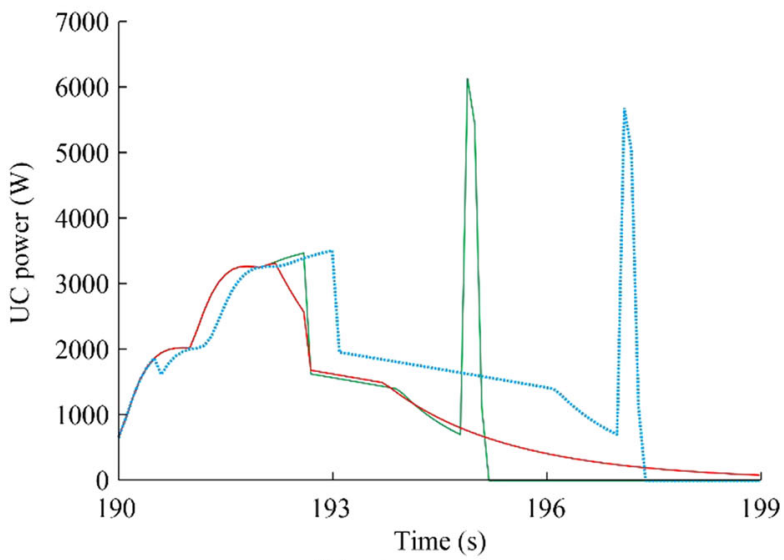

(b) Discharging mode

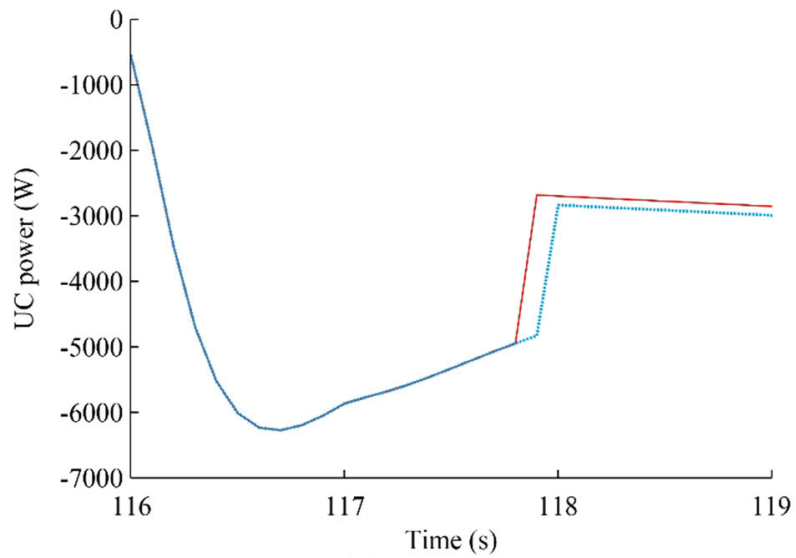

(c) Charging mode

$-P_{U C, U} ;-P_{U C, P} ;-P_{U C, W}$

Fig. 4 UC power share for the whole, an interval during discharging mode, and charging mode of FTP driving cycle, for $P_{U C, U}, P_{U C, P}$, $P_{U C, W}$ strategies

This is evident from observing the battery power consumption shown in Fig. 6 and around 192 s, which shows that the battery power consumption is the lowest for the wavelet PDS, followed by the SoP PDS, and is the highest for the UC-based method. It is noticed that there are several battery power peaks associated with the UC-based PDS 


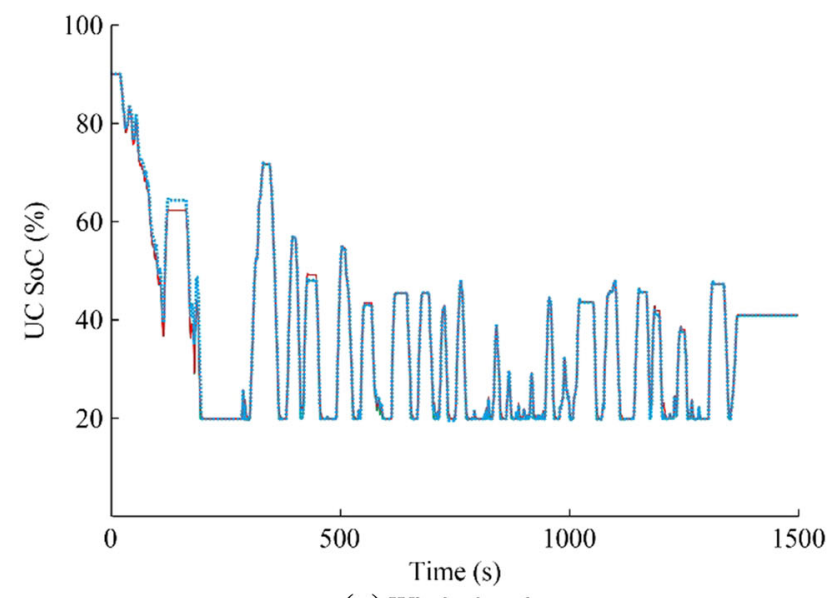

(a) Whole duration

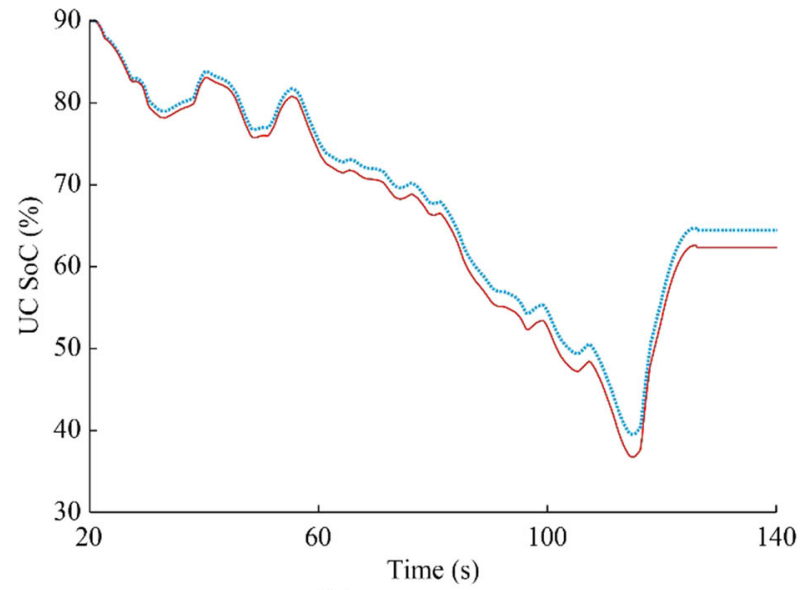

(b) Interval duration

$$
-S o C_{U C, U} ;-S o C_{U C, P} ;-S_{U C, W}
$$

Fig. 5 UC SoC for the whole and interval duration of FTP driving cycle, for UC-based $\left(S o C_{U C, U}\right)$, SoP-based $\left(S o C_{U C, P}\right)$ and wavelet based $\left(S o C_{U C, W}\right)$ strategies

which is not desirable in terms of the battery lifetime. Overall, the wavelet and SoP PDSs show comparable results. As discussed, the wavelet PDS moderates the battery power consumption by effectively engaging the UC. This leads to lower battery SoC variations, compared with the other PDS strategies. Figure 7a shows the battery SoC for the duration of ten FTP driving cycles. When operating under the UC-based PDS strategy, the battery reaches the lower limit of $20 \%$ firstly, compared with the other two strategies.

The wavelet and SOP PDSs show comparable results. Therefore, these PDSs enable the motorcycle to drive for a longer range, compared with the UC-based method. This is possible due to the better management of the UC SoC, as shown in Fig. 5.

After showing the superior performance of the proposed wavelet PDS, compared with the UC-based and SoP-based PDSs, Fig. $7 \mathrm{~b}$ compares the performance of the proposed

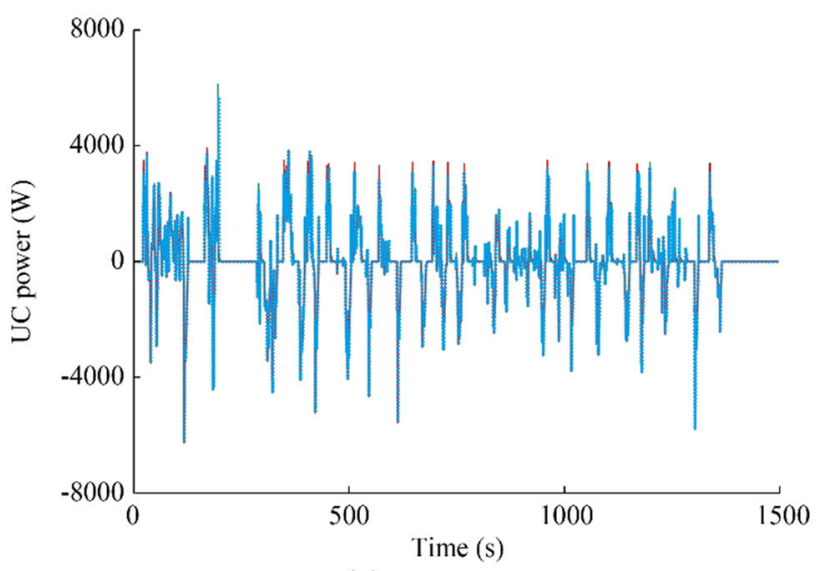

(a) Whole duration

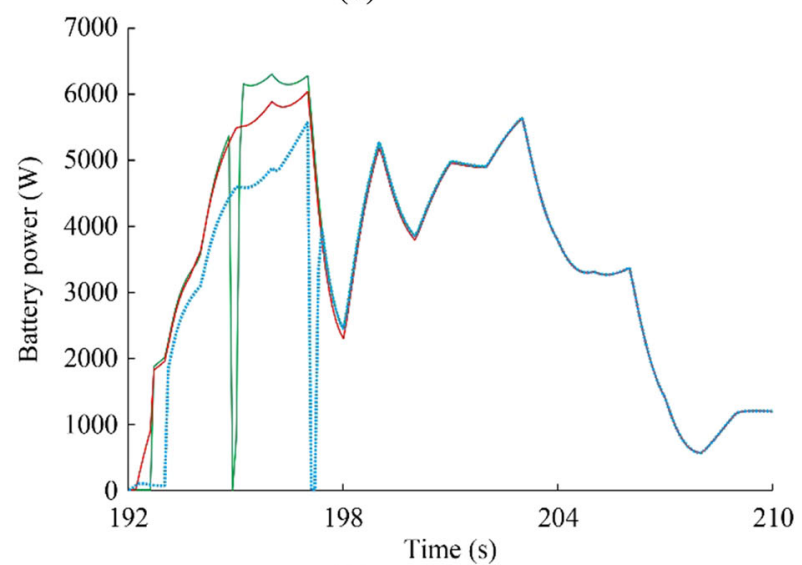

(b) Interval duration

$-P_{B a t, U} ;-P_{B a t, P} ;-P_{B a t, W}$

Fig. 6 Battery power consumption for the whole and interval duration of FTP cycle, for UC-based $\left(P_{B a t, U}\right)$, SoP-based $\left(P_{B a t, P}\right)$ and wavelet based $\left(P_{B a t, W}\right)$ strategies

HESS with an ESS. The battery/UC SoC of the proposed wavelet PDS and the battery SoC of an ESS are shown for the FTP driving cycle. As can be seen, the battery SoC for the wavelet remains above the one for the ESS. This is due to the UC contribution during the discharging/charging modes. The higher level of battery SoC provides higher mileage of the electric motorcycle equipped with the wavelet PDS, compared with the one equipped with an ESS.

Figure 8 shows the battery current fed to/from the battery during the whole and interval duration of the FTP driving cycle.

Note that the overall current fed to/drawn from the battery is the highest for the $\operatorname{ESS}\left(I_{B a t, B}\right)$, and is the least for the proposed wavelet HESS $\left(I_{B a t, W}\right)$.

Performance comparison for different ESSs is summarized in Table 8 . As can be seen, the battery lifetime for the ESS is 4.95 years, and is 10.66 years for the HESS equipped with SoP controller. On the other hand, the battery lifetime for the proposed HESS equipped with wavelet 


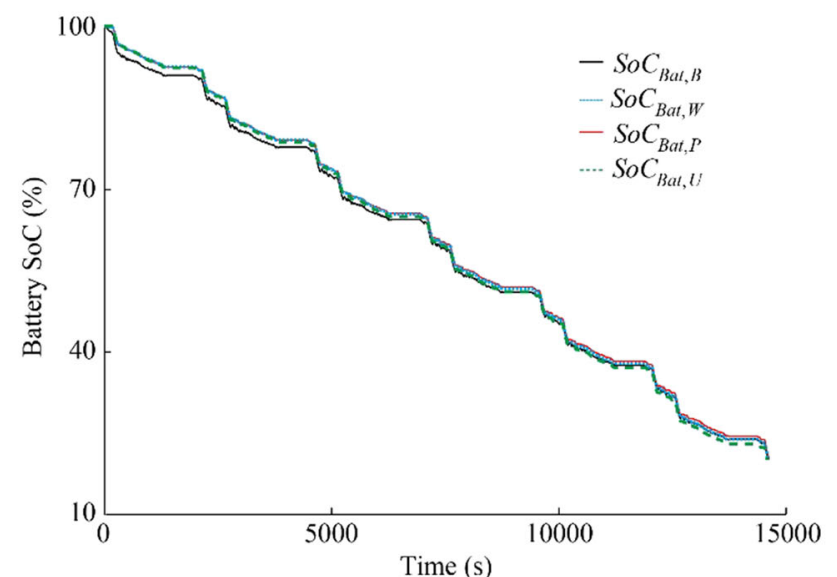

(a) Battery SoC for duration of 10 FTP cycles

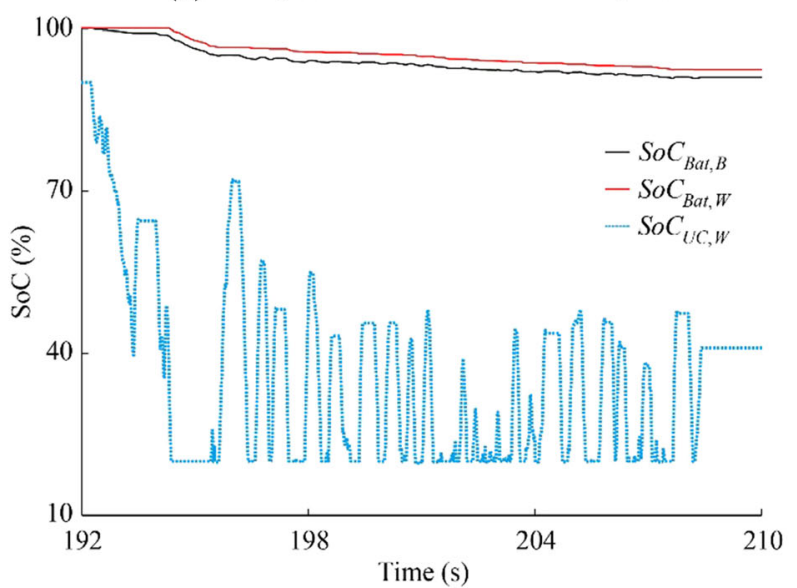

(b) Battery SoC and UC SoC during FTP driving cycle

Fig. 7 Battery SoC and UC SoC

controller is 10.93 years, which shows an improvement of $120 \%$ and $3 \%$, compared with the other two strategies, respectively.

On the other hand, the number of battery replacement for a 10-year period of time is zero for the HESS equipped with the wavelet controller, while the ESS needs to be replaced two times. In terms of associated costs, the initial cost of the proposed HESS equipped with wavelet controller is about 1000 \$ more than that of the ESS, while the total cost of the proposed HESS is about 1500 \$ lower than that of the ESS. Finally, the energy recovery for the ESS is 102.5 Wh, while it is $126.3 \mathrm{Wh}$ for the proposed HESS equipped with wavelet controller, which shows an improvement of $23 \%$. This value is slightly higher than the one obtained for the SoP-based controller. Overall, the results demonstrate the effectiveness of the proposed HESS equipped with wavelet controller compared with the ESS, and the HESS equipped with UC-based and SoP-based controllers. This makes it suitable to replace the ESS and the latter methods.

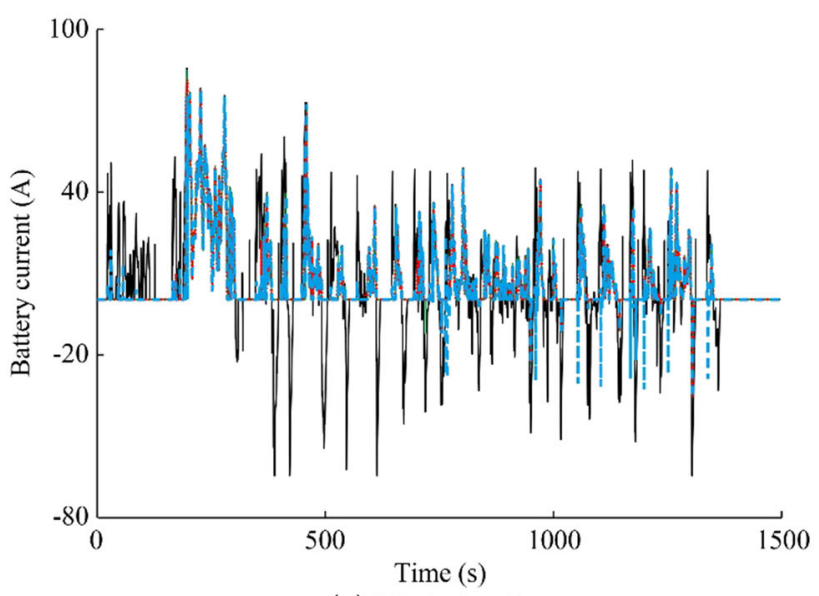

(a) Whole duration

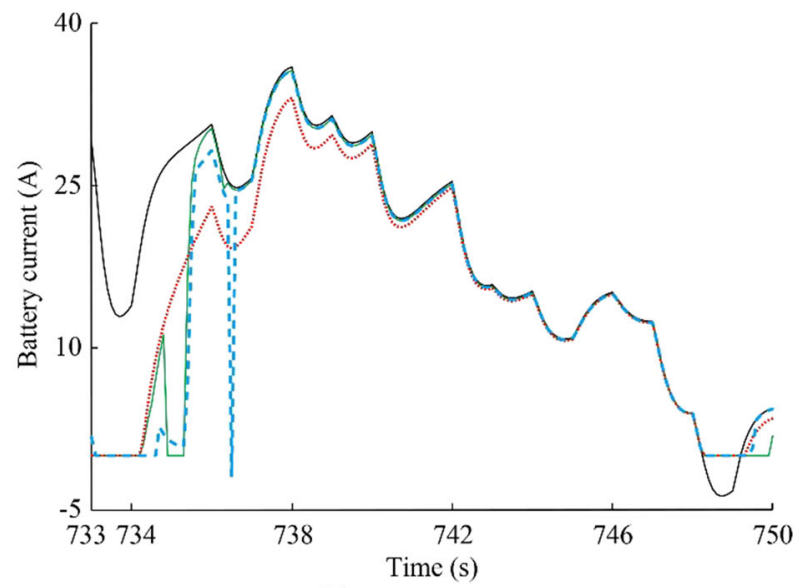

(b) Interval duration

$$
-I_{B a t, B} ;-I_{B a t, P} ; \cdots I_{B a t, W} ;-I_{B a t, U}
$$

Fig. 8 Battery current for the whole and interval duration of the FTP cycle, for ESS $\left(I_{B a t, B}\right)$, UC-based $\left(I_{B a t, U}\right)$, SoP-based $\left(I_{B a t, P}\right)$ and wavelet based $\left(I_{B a t, W}\right)$ strategies

Table 8 Comparison of different energy storage performance

\begin{tabular}{llll}
\hline Performance & Battery & $\begin{array}{l}\text { HESS (SoP- } \\
\text { based) }\end{array}$ & $\begin{array}{l}\text { HESS } \\
\text { (Wavelet) }\end{array}$ \\
\hline $\begin{array}{l}\text { Battery lifetime } \\
\quad \text { (year) }\end{array}$ & 4.95 & 10.66 & 10.93 \\
$\begin{array}{l}\text { Replacement } \\
\text { Initial cost (\$) }\end{array}$ & 2 & 0 & 0 \\
$\begin{array}{l}\text { Total cost (\$) } \\
\text { Energy recovery }\end{array}$ & 1250 & 2255 & 2255 \\
$\quad 1$ Wh) & 102.5 & 126.2 & 2255 \\
\hline
\end{tabular}

\section{Conclusion}

A new frequency-based control strategy is proposed for power distribution management of an HESS. The proposed controller is designed based on the wavelet filter. If a certain input power level reaches $(1800 \mathrm{~W})$, the wavelet 
controller is engaged and the battery is assigned to provide the low frequency portion of the demand power, while the UC provides the high frequency portion. The frequency filter is a multi-level Haar wavelet filter with 29-level decomposition and reconstruction. An integer genetic algorithm optimization technique is employed to find the optimal level of wavelet decomposition as well as the optimal activation power.

As a case study, the powertrain of an electric motorcycle is modeled and examined for evaluating the ESS. The motorcycle is studied during the FTP driving cycle. The $\mathrm{LiFePO}_{4}$ battery type is considered and its life loss model based on the battery current is studied. To show the effectiveness of the proposed wavelet-based power management strategy, two other strategies are presented and studied: a UC-based strategy and a SoP-based strategy. The results show that the UC peak fluctuations of battery power are moderated by adding the UC. Moreover, the proposed HESS equipped with wavelet provides lower peaks of power fed to/drawn from the battery, compared with the other two HESSs. This is suitable in terms of improving the battery lifetime. Therefore, the battery life loss and number of battery replacement of the HESS equipped with the wavelet controller are the best. Specifically, there is an improvement of $120 \%$ and $3 \%$ for the battery lifetime, compared with ESS and SoP-based method. The energy recovery for the proposed algorithm is improved by $23 \%$, compared with ESS and is slightly higher than the one for SoP-based controller. The initial cost of HESS is about 1000 \$ higher than that of the ESS, while the 10-year overall cost of HESS with wavelet strategy is about 1500 \$ lower than the ESS case.

Future work could be done by employing sophisticated control strategies for power distribution between battery and UC to improve the battery life cycle. In addition, the effect of battery temperature can be modeled to improve the life cycle estimation.

Acknowledgements This work was supported by the Automotive Engineering Research Center (AERC) of Iran University of Science and Technology (IUST) and the Vehicle, Fuel and Environment Research Institute (VFERI) of The University of Tehran.

Open Access This article is distributed under the terms of the Creative Commons Attribution 4.0 International License (http://creativecommons. org/licenses/by/4.0/), which permits unrestricted use, distribution, and reproduction in any medium, provided you give appropriate credit to the original author(s) and the source, provide a link to the Creative Commons license, and indicate if changes were made.

\section{References}

[1] Tuayharn K, Kaewtatip P, Ruangjirakit K et al (2015) ICE motorcycle and electric motorcycle: environmental and economic analysis. SAE technical paper. No. 2015-01-0100
[2] Zhang S, Mishra Y, Ledwich G et al (2013) The operating schedule for battery energy storage companies in electricity market. J Mod Power Syst Clean Energy 1(3):275-284

[3] Karandikar PB, Talange DB, Mhaskar UP et al (2012) Development, modeling and characterization of aqueous metal oxide based supercapacitor. Energy 40(1):131-138

[4] Ye M, Bai ZF, Cao BG (2008) Energy recovery for battery electric vehicles. Proc Inst Mech Eng Part D J Automob Eng 222(10): 1827-1839

[5] Amiri M, Esfahanian M, Hairi-Yazdi MR et al (2009) Minimization of power losses in hybrid electric vehicles in view of the prolonging of battery life. J Power Sources 190(2):372-379

[6] Liu W, Drobnik J (2011) Challenges, opportunities and future of electric vehicles. In: Proceedings of European electric vehicle congress (EEVC), Brussels, Belgium, 26-28 October 2011

[7] Chemali E, Preindl M, Malysz P et al (2016) Electrochemical and electrostatic energy storage and management systems for electric drive vehicles: state-of-the-art review and future trends. IEEE J Emerg Sel Top Power Electron 4(3):1117-1134

[8] Geetha A, Subramani C (2017) A comprehensive review on energy management strategies of hybrid energy storage system for electric vehicles. Int J Energy Res 41(13):1817-1834

[9] Liu W, Niu S, Xu H (2017) Optimal planning of battery energy storage considering reliability benefit and operation strategy in active distribution system. J Mod Power Syst Clean Energy 5(2):177-186

[10] Zhang S, Xiong R, Cao J (2016) Battery durability and longevity based power management for plug-in hybrid electric vehicle with hybrid energy storage system. Appl Energy 179:316-328

[11] Yao L, Yang B, Cui H et al (2016) Challenges and progresses of energy storage technology and its application in power systems. J Mod Power Syst Clean Energy 4(4):519-528

[12] Bubna P, Advani SG, Prasad AK (2012) Integration of batteries with ultracapacitors for a fuel cell hybrid transit bus. J Power Sources 199:360-366

[13] Gu W, Yuan XD, Zhang KF (2018) Fully distributed control to coordinate charging efficiencies for energy storage systems. J Mod Power Syst Clean Energy 6(5):1015-1024

[14] Allègre AL, Bouscayro A, Trigui R (2009) Influence of control strategies on battery/supercapacitor hybrid energy storage systems for traction applications. In: Proceedings of IEEE vehicle power and propulsion conference, Dearborn, USA, 7-10 September 2009, pp 213-220

[15] Masih-Tehrani M, Yahyaei R (2017) Study of lithium battery thermal effect on battery and hybrid battery/ultra-capacitor sizing for an electric vehicle. J Eng Technol 6:85-99

[16] Li M, Xu H, Li W et al (2016) The structure and control method of hybrid power source for electric vehicle. Energy 112:1273-1285

[17] Masih-Tehrani M, Ha'iri-Yazdi MR, Esfahanian V et al (2013) Optimum sizing and optimum energy management of a hybrid energy storage system for lithium battery life improvement. J Power Sources 244:2-10

[18] Masih-Tehrani M, Hairi-Yazdi MR, Esfahanian V (2014) Power distribution development and optimization of hybrid energy storage system. Int J Automot Eng 4:675-684

[19] Amjadi Z, Williamson SS (2010) Power-electronics-based solutions for plug-in hybrid electric vehicle energy storage and management systems. IEEE Trans Ind Electron 57(2):608-616

[20] Zhang S, Xiong R, Sun F (2017) Model predictive control for power management in a plug-in hybrid electric vehicle with a hybrid energy storage system. Appl Energy 185:1654-1662

[21] Pavković D, Lobrović M, Hrgetić M (2016) A design of cascade control system and adaptive load compensator for battery/ 
ultracapacitor hybrid energy storage-based direct current microgrid. Energy Convers Manag 114:154-167

[22] Herrera V, Milo A, Gaztañaga $\mathrm{H}$ et al (2016) Adaptive energy management strategy and optimal sizing applied on a batterysupercapacitor based tramway. Appl Energy 169:831-845

[23] Florescu A, Bacha S, Munteanu I et al (2015) Adaptive frequency-separation-based energy management system for electric vehicles. J Power Sources 280:410-421

[24] Tavakol-Sisakht S, Barakati SM (2016) Energy manegement using fuzzy controller for hybrid electrical vehicles. J Intell Fuzzy Syst 30(3):1411-1420

[25] Vinot E, Trigui R (2013) Optimal energy management of HEVs with hybrid storage system. Energy Convers Manag 76:437-452

[26] Yuan Y, Sun C, Li M et al (2015) Determination of optimal supercapacitor-lead-acid battery energy storage capacity for smoothing wind power using empirical mode decomposition and neural network. Electr Power Syst Res 127:323-331

[27] Hredzak B, Agelidis VG, Demetriades G (2015) Application of explicit model predictive control to a hybrid battery-ultracapacitor power source. J Power Sources 277:84-94

[28] Song Z, Hofmann H, Li J et al (2015) Optimization for a hybrid energy storage system in electric vehicles using dynamic programing approach. Appl Energy 139:151-162

[29] Chengchen S, Yue Y, Mengting L et al (2015) Capacity optimization of hybrid energy storage systems in microgrid using empirical mode decomposition and neural network. Autom Electr Power Syst 39(8):19-26

[30] Masih-Tehrani M, Dahmardeh M (2018) A novel power distribution system employing state of available power estimation for a hybrid energy storage system. IEEE Trans Ind Electron 65(8):6676-6685

[31] Erdinc O, Vural B, Uzunoglu M (2009) A wavelet-fuzzy logic based energy management strategy for a fuel cell/battery/ultracapacitor hybrid vehicular power system. J Power Sources 194(1):369-380

[32] Aghajani A, Kazemzadeh R, Ebrahimi A (2016) A novel hybrid approach for predicting wind farm power production based on wavelet transform, hybrid neural networks and imperialist competitive algorithm. Energy Convers Manag 121:232-240

[33] Mellit A, Kalogirou SA, Hontoria L et al (2009) Artificial intelligence techniques for sizing photovoltaic systems: a review. Renew Sustain Energy Rev 13(2):406-419

[34] Li X, Li Y, Han X et al (2011) Application of fuzzy wavelet transform to smooth wind/PV hybrid power system output with battery energy storage system. Energy Proc 12:994-1001

[35] Kuperman A, Aharon I, Kara A et al (2011) A frequency domain approach to analyzing passive battery-ultracapacitor hybrids supplying periodic pulsed current loads. Energy Convers Manag 52(12):3433-3438

[36] Panday A, Bansal HO (2016) Multi-Objective optimization in battery selection for hybrid electric vehicle applications. J Electr Syst 12(2):325-343

[37] Yang CC, Jang JH, Jiang JR (2016) Study of electrochemical performances of lithium titanium oxide-coated LiFePO 4/C cathode composite at low and high temperatures. Appl Energy 162:1419-1427

[38] Esfahanian M, Safaei A, Nehzati H et al (2014) Matlab-based modeling, simulation and design package for eletric, hydraulic and flywheel hybrid powertrains of a city bus. Int $\mathrm{J}$ Automot Technol 15(6):1001-1013

[39] Masih-Tehrani M, Hairi-Yazdi MR, Esfahanian V et al (2012) Development of a hybrid energy storage sizing algorithm associated with the evaluation of power management in different driving cycles. J Mech Sci Technol 26(12):4149-4159

[40] Masih-Tehrani M, Esfahanian M, Nehzati H et al (2012) Design and simulation of a hybrid flywheel bus. In:
Proceedings of international conference on applications and design in mechanical engineering, Penang, Malaysia, 27-28 February 2012

[41] Safaei A, Ha'iri-Yazdi MR, Esfahanian V et al (2014) Designing an intelligent control strategy for hybrid powertrains utilizing a fuzzy driving cycle identification agent. Proc Inst Mech Eng Part D J Automob Eng 229(9):1169-1188

[42] Wang Y, Liu C, Pan R et al (2017) Modeling and state-ofcharge prediction of lithium-ion battery and ultracapacitor hybrids with a co-estimator. Energy 121:739-750

[43] Wang J, Liu P, Hicks-Garner J et al (2011) Cycle-life model for graphite-LiFePO4 cells. J Power Sources 196(8):3942-3948

[44] Bloom I, Cole BW, Sohn JJ et al (2001) An accelerated calendar and cycle life study of Li-ion cells. J Power Sources 101(2):238-247

[45] Masih-Tehrani M, Bazargan D, Hairi-Yazdi MR et al(2011) Performance analysis of hybrid energy storage in different driving cycles. In: Proceedings of 2 nd power electronics, drive systems and technologies conference, Tehran, Iran, 16-17 February 2011, pp 330-335

[46] Burke A (2010) Ultracapacitor technologies and application in hybrid and electric vehicles. Int J Energy Resour 34(2):133-151

[47] Plett GL (2004) High-performance battery-pack power estimation using a dynamic cell model. IEEE Trans Veh Technol 53(5):1586-1593

[48] Waag W, Fleischer C, Sauer DU (2014) Critical review of the methods for monitoring of lithium-ion batteries in electric and hybrid vehicles. J Power Sources 258:321-339

[49] Farmann A, Sauer DU (2016) A comprehensive review of onboard state-of-available-power prediction techniques for lithiumion batteries in electric vehicles. J Power Sources 329:123-137

[50] Nguyen TQ, Vaidyanathan PP (1990) Structures for M-channel perfect-reconstruction FIR QMF banks which yield linear-phase analysis filters. IEEE Trans Acoust 38(3):433-446

[51] Zhang X, Mi CC, Masrur A et al (2008) Wavelet-transformbased power management of hybrid vehicles with multiple onboard energy sources including fuel cell, battery and ultracapacitor. J Power Sources 185(2):1533-1543

[52] Wang X (2006) Moving window-based double haar wavelet transform for image processing. IEEE Trans Image Process 15(9):2771-2779

[53] Masih-Tehrani M, Ebrahimi-Nejad S (2018) Hybrid genetic algorithm and linear programming for bulldozer emissions and fuel-consumption management using continuously variable transmission. J Constr Eng Manag 144(7):1-9

Masoud MASIH-TEHRANI received his Ph.D. degree in mechanical engineering with major in hybrid energy storage systems from University of Tehran (UT), Tehran, Iran, in 2013. He is currently a faculty member and assistant professor at the school of automotive engineering, Iran University of Science and Technology (IUST), Tehran, Iran. His research interests are hybrid energy storage systems, hybrid flywheel vehicles, heavy duty vehicles, vehicle suspension systems, and vehicle control systems.

Mohammad Reza HA'IRI YAZDI received his B.Sc. and M.Sc. degrees from Amirkabir University of Technology, Tehran, Iran in 1985 and 1987, respectively, and his Ph.D. degree from Imperial College, London, England in 1990. He was a postdoctoral researcher at Rutherford-Appleton Research Laboratory, Oxford, England from 1990 to 1991 . He is currently a Professor of Dynamic Systems and Control in the School of Mechanical Engineering, College of Engineering, University of Tehran, Iran. His research interests include simulation, design and control of dynamic systems, robotics control, vehicle dynamics, modular robotic systems, and robot task and motion planning. 
Vahid ESFAHANIAN received his B.Sc. degree from the University of Illinois at Chicago, USA in 1982 and his M.Sc. degrees and Ph.D. from the Ohio State University, USA, in 1985 and 1991, respectively. He is now a Full Professor in the School of Mechanical Engineering and the head of Vehicle, Fuel, and Environment Research Institute (VFERI), University of Tehran, Iran. His research interests include $\mathrm{CFD}$, battery simulations and hybrid vehicles.

Masoud DAHMARDEH received Ph.D. degree in electrical engineering with major in microelectro-mechanical systems (MEMS) from The University of British Columbia (UBC), Vancouver, Canada, in 2014. He is currently a faculty member and assistant professor at the school of automotive engineering, Iran University of science and technology, Tehran, Iran. His research interests are automotive electronics, microfabrication, micro-electro-mechanical systems, carbon nanotubes (CNT), shape memory alloys (SMA), photonic crystals, active integrated antennas, and radiation.

Hassan NEHZATI received his B.Sc. and M.Sc. degrees from University of Tehran, Iran at 2010 and 2015, respectively, in mechanical engineering. Since 2005 until now, he is with vehicle, fuel and environment research institute (VFERI), University of Tehran, Iran. His research interests include hybrid vehicles and battery management systems. 